\title{
Formulation of Tenebrio Molitor (Mealworm) Larvae Pellet for Oreochromis Niloticus (Nile Tilapia) Feed Production
}

\author{
Vasquez AI ${ }^{1}$, Perez RM1 ${ }^{1}$ and Genelyn GM1,2* \\ ${ }^{1}$ Department of Biological Sciences, College of Science and Mathematics Western \\ Mindanao State University, Philippines \\ ${ }^{2}$ Research Utilization, Publication and Information Dissemination (RUPID) Office, \\ Western Mindanao State University, Philippines
}

\section{Research Article \\ Volume 3 Issue 3}

Received Date: October 08, 2019

Published Date: November 11, 2019

DOI: $10.23880 /$ ijoac- 16000174

*Corresponding author: Genelyn G. Madjos, Department of Biological Sciences, College of Science and Mathematics Western Mindanao State University, Blk 8, Lot 4, Kalambuan Housing Project, Maasin, Zamboanga City, Philippines, Email: ggmadjos@gmail.com

\section{Abstract}

Mealworms are larval stages of darkling beetles (Tenebrio molitor) which are considered major agricultural pests; however, recently, they are seen as potential fish feeds in the field of aquaculture. This present study aimed to determine the effect of the varying feed formulation of Tenebrio molitor (mealworm) larvae on the growth performance of Oreochromis. niloticus (nile tilapia) and to produce a mealworm pellet out of the study. One hundred eighty (180) juvenile nile tilapia were assigned in net cages in a Randomized Complete Block Design (RCBD) and were fed thrice daily (6:00AM; $12 \mathrm{NOON} ; 6: 00 \mathrm{PM})$ for a month with different feed formulations. The formulations were: treatment 1 (T1) $=25 \mathrm{~g}$ mealworm larvae $+40 \mathrm{~g}$ cassava starch $+33 \mathrm{ml}$ water; treatment $2(\mathrm{~T} 2)=50 \mathrm{~g}$ mealworm larvae $+40 \mathrm{~g}$ cassava starch +38 $\mathrm{ml}$ water; treatment $3(\mathrm{~T} 3)=75 \mathrm{~g}$ mealworm larvae $+40 \mathrm{~g}$ cassava starch $+46 \mathrm{ml}$ water; and treatment 4 (T4) as the control (commercial fish pellets). One-way Analysis of Variance (ANOVA) revealed that there is a highly significant difference ( $p$ value: 0.000 ) in the mean gain weight of $O$. niloticus between and within groups after being fed with the different feed formulations with T1 obtaining the highest mean weight gain (13.62grams). Post Hoc Analysis (LSD) revealed that the weight gain of 0 . niloticus (nile tilapia) of T1 was highly significant at $\alpha \leq 0.001$. In terms of the storability of the pellet, it did not disintegrate within the time span and can be stored up to six (6) months. Considering that the Philippines imports almost half a billion dollars' worth of other fish meals such as soybean meal at all seasons of the year, treatment 1 (25g mealworm larvae, 40g cassava starch and $33 \mathrm{ml}$ water) has the potential as an alternative protein feed material in the country.

Keywords: Mealworm; Fish Pellet; Aquaculture; Darkling Beetles 


\section{International Journal of Oceanography \& Aquaculture}

\section{Introduction}

The supply of fish in the world's vast oceans once seemed sustainable. However, in the past three decades, unregulated harvesting and trade have increased dramatically, leading to lower supply in response to its demand [1]. According to Makkar, et al. (2014) as cited in Thevenot [2], as the human population tends to increase, greater demand occurs for food and other resources, particularly animal protein.

Aquaculture, which aims to target food sustainability, plays significant role in many countries by providing a higher income, better nutrition and better employment opportunities. It has attempted to fill the gap between supply and demand. But as the global appetite for fish continues to increase, current trends such as overfishing and large commercial industry in the fish sector pose serious risks to the environment, to the well-being of people and to the viability of the fish sector itself [1].

In the Philippines, the current condition of fisheries is at threat. Increased demand for fish and population growth continue to drive lesser production in fisheries. Protein deficiency among fishing communities is now increasing at an alarming rate [3]. The Philippine Council for Agriculture, Aquatic and Natural Resources Research and Development (PCAARRD) under the Department of Science and Technology (DOST) recognized this problem through its SIPAG (Strategic Industry S\&T Program for Aquaculture) program. Accordingly, feed production plays a very important role in the field of aquaculture as it reduced the natural food in the hatchery.

Currently, practical formulations containing golden apple snail, local meal, copra and cassava meal and rice bran are currently being evaluated in field trials to compare performance with commercial feed as well as to determine the appropriate ingredients and composition. This is due to the expected higher cost and future disruptions in the supply of feed ingredients in the feed industry [2]. Thus, aquaculture studies are focus on alternative sources of feeds that are cheaper and comparable in terms of nutritive value to other commonly used one such as soymeal and fishmeal [4].

Mealworms are larval stages of darkling beetles (Tenebrio molitor) which are considered major agricultural pests; however, recently, they are seen as potential fish feeds in the field of aquaculture. According to Hussain [4], mealworms have high potential as valuable protein feed ingredient with protein content of
44-70\%. Moreover, mealworm having better nutrient profile and digestibility could be used to produce economical fish meal feed formulation. Considering that the Philippines imports almost half a billion dollars' worth of other fish meals such as soybean meal at all seasons of the year, other alternative fish feed formulations can replace up to $50 \%$ of other protein feed material in the country (DOST- PCAARRD, 2017).

Nile tilapia (Oreochromis niloticus) is a predominant fish and second most important cultured fish in the Philippines. About 259, 045 metric tons of tilapia was produced annually (SSA 2017 in Seafood Trade Intelligence Portal). Commercial tilapia aquaculture has improved being aware of the importance of adopting innovative husbandry technologies. These include the use of novel feed ingredients, improving the quality of industrial aqua feeds and adopting cost-effective feeding strategies [5].

O. niloticus juveniles are omnivorous. In most tilapia farms where pellets are dry or moist feeds are used, spreading by hand is the preferred method of feeding. Being active swimmers, tilapia will readily swim to the edge of the pond or cage where the feed is being spread [6]. With the expansion in intensified aquaculture, interest for more proficient aqua-feed is rising. This involves the principle operating cost in fish generation [7]. With these, this study was conceptualized which specifically aimed to determine the effect of the varying feed formulation of T. molitor (mealworm) larvae on the growth performance of 0 . niloticus (nile tilapia) and be able to produce a mealworm pellet out of the study.

\section{Materials and Method}

\section{Research Samples}

Tenebrio molitor larvae (mealworm) were formulated as feed pellet (Figure 1).

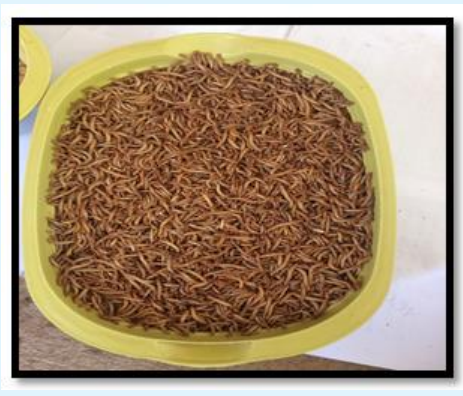

Figure 1: Dried mealworm larvae. 


\section{International Journal of Oceanography \& Aquaculture}

The test organism used in the study to determine the effectiveness of the different mealworm larvae feed formulations is the Oreochromis niloticus (nile tilapia). This test organism was selected knowing it is the second highly consumable fish in the Philippines, yet there is still a need of improvement in terms of feeding techniques.

\section{Research Design and Layout}

Randomized Complete Block Design (RCBD) was used as the research design. The assigning of specimens was through fish bowl method. Since the samples are mobile, assigning of the fish to the different treatments in each block followed immediately after each pick of random numbering. There were three (3) replicates employed, represented by blocks and 15 subsamples in the following four (4) treatments as modified from Dedeke, et al. [8]. Thus, a total of 180 juvenile nile tilapia were utilized in the study.

\section{Preparation of Powdered Mealworm}

Dried mealworm larvae were induced with $5 \%$ salt solution, followed by sun-drying method for 2 days. After which, grinding process was conducted by the use of grinding machine and was placed in a clean container.

\section{Optimization of Pellets}

For treatment 1, a total of 25 grams of powdered mealworm were mixed with 40 grams of cassava starch in a clean bowl. The mixture was added with $33 \mathrm{ml}$ of water while being introduced to low fire. Then mixture was set to create dough like appearance. After which, the mixture was placed in a clean plate (if necessarily). The procedure done same goes with treatment 2 (with 50 grams of powdered mealworm and $38 \mathrm{ml}$ of water) and treatment 3 (with 75 grams of powdered mealworm and $46 \mathrm{ml}$ of water) except treatment 4 because $\mathrm{T} 4$ served as the positive control (commercial fish pellets). Thereafter, the formed mixture was fashioned on its designated shape. Electric meat grinder with $5-\mathrm{mm}$ diameter in size extruded the dough and the extruded dough was cut using knife manually. Then, the processed pellets were placed on a dry flat plate and allowed to cool in an air-dry manner. Lastly, the formulated mealworm fish pellet was placed in its corresponding container [9].

\section{Experimental Set-up}

A total of 12 net cages were installed in the pond having the size of $1.5 \times 1.5$ meter. Walkways were also placed in between cages to facilitate the feeding [10]. The following feed formulations were administered to the nile tilapia separated by net cages:

$$
\begin{gathered}
\mathrm{T} 1=25 \mathrm{~g} \text { mealworm larvae }+40 \mathrm{~g} \\
\text { cassava starch }+33 \mathrm{ml} \text { water } \\
\mathrm{T} 2=50 \mathrm{~g} \text { mealworm larvae }+40 \mathrm{~g} \\
\text { cassava starch }+38 \mathrm{ml} \text { water } \\
\mathrm{T} 3=75 \mathrm{~g} \text { mealworm larvae }+40 \mathrm{~g} \\
\text { cassava starch }+46 \mathrm{ml} \text { water } \\
\mathrm{T} 4=\text { commercial fish pellets (control) }
\end{gathered}
$$

O. niloticus were fed thrice daily (6:00AM; $12 \mathrm{NOON}$; 6:00PM) for a month with these treatments.

\section{Results and Discussion}

Mean weight gain is the commonly used measure in evaluating the growth performance in aquaculture industry [11]. Table 1 shows the mean weight (grams) gain of $O$. niloticus fed with different feeding formulas of $T$. molitor (mealworm) larvae.

\begin{tabular}{|c|c|c|c|}
\hline Treatments & Mean & N & Std. Deviation \\
\hline Treatment 1 & 13.6222 & 45 & 8.18268 \\
\hline Treatment 2 & 10.2556 & 45 & 6.33409 \\
\hline Treatment 3 & 7.3778 & 45 & 4.67969 \\
\hline Treatment 4 & 8.4667 & 45 & 5.85274 \\
\hline Total & 9.9306 & 180 & 6.76414 \\
\hline
\end{tabular}

Table 1: Mean weight (grams) gain of $O$. niloticus fed with different feeding formulas of T. molitor (mealworm) larvae.

Treatment 1 has the highest mean gain weight among all treatments. Thus, this implies that $O$. niloticus fed with $25 \mathrm{~g}$ mealworm larvae $+40 \mathrm{~g}$ cassava starch $+33 \mathrm{ml}$ water (T1) is the preferred formulation in terms of evaluating the growth performance. Further, a grand total of 9.93 grams of the mean justified that all $O$. niloticus have gained weight when treated with different $T$. molitor feeding formulations (T1 $=25 \mathrm{~g}$ mealworm larvae $+44 \mathrm{~g}$ cassava starch $+33 \mathrm{ml}$ water $\mathrm{T} 2=50 \mathrm{~g}$ mealworm larvae + $40 \mathrm{~g}$ cassava starch $+38 \mathrm{ml}$ water $\mathrm{T} 3=75 \mathrm{~g}$ mealworm larvae $+40 \mathrm{~g}$ cassava starch $+46 \mathrm{ml}$ water). 


\section{International Journal of Oceanography \& Aquaculture}

Table 2 shows the Analysis of Variance (ANOVA) results in the mean weight of $O$. niloticus (nile tilapia) fed

with different T. molitor (mealworm) larvae feed formulations.

\begin{tabular}{|c|c|c|c|c|c|}
\hline & Sum of Squares & df & Mean Square & F-statistic & p-value \\
\hline Between Groups & 1007.715 & 3 & 335.905 & 8.231 & $.000^{* *}$ \\
\hline Within Groups & 7182.167 & 176 & 40.808 & & \\
\hline Total & 8189.882 & 179 & & & \\
\hline
\end{tabular}

Table 2: ANOVA results in terms of the mean gain weight (grams) of 0 . niloticus (nile tilapia) fed with different feed formulations.

**highly significant at $\alpha \leq 0.001$

There is a highly significant difference ( $p$ value: 0.000 ) in the mean gain weight (grams) of $O$. niloticus between and within groups after being fed with the different feed formulations. These results are supported by the Food and Agriculture Organization [6], where it stated that nile tilapia greater than 25 grams would require less dietary protein for growth and can utilize even higher levels of carbohydrates as a source of energy. With this, compared to formulated feeds, T1 (25 grams of mealworm larvae (as a source of protein) and 40 grams of cassava starch (as a source of carbohydrate other than as binding agent) supplied the approximate amount of nutrition that the $O$. niloticus (nile tilapia) requires.

Table 3 shows the Post Hoc Analysis (Least Significant Difference - LSD) on the treatment effects on $O$. niloticus (nile tilapia) fed with T. molitor (mealworm) larvae feed formulations.

\begin{tabular}{|c|l|c|c|c|c|c|}
\hline \multicolumn{2}{|c|}{ Treatments } & Mean Difference (Final - Initial) & Std. Error & \multirow{2}{*}{ Sig. } & \multicolumn{2}{c|}{ 95\% Confidence Interval } \\
\cline { 5 - 7 } & & & & Lower Bound & Upper Bound \\
\hline \multirow{3}{*}{ Treatment 1 } & Treatment 2 & 3.36667 & 1.34673 & $.013^{*}$ & 0.7089 & 6.0245 \\
\cline { 2 - 7 } & Treatment 3 & 6.24444 & 1.34673 & $.000^{* *}$ & 3.5866 & 8.9023 \\
\cline { 2 - 7 } & Treatment 4 & 5.15556 & 1.34673 & $.000^{* *}$ & 2.4977 & 7.8134 \\
\hline \multirow{2}{*}{ Treatment 2 } & Treatment 3 & 2.87778 & 1.34673 & $.034^{*}$ & 0.22 & 5.5356 \\
\cline { 2 - 7 } & Treatment 4 & 1.78889 & 1.34673 & 0.186 & -0.8689 & 4.4467 \\
\hline Treatment 3 & Treatment 4 & -1.08889 & 1.34673 & 0.42 & -1.5689 & 3.7467 \\
\hline
\end{tabular}

Table 3: Post Hoc Analysis (LSD) on the Treatment Effects on O. niloticus (nile tilapia) fed with T. molitor (mealworm) larvae feed formulations.

${ }^{* *}$ significant at alpha $=0.001 ;$ *significant at alpha $=0.05$

Table 3 showed that $25 \mathrm{~g} \mathrm{MW}+40 \mathrm{~g} \mathrm{CS}+33 \mathrm{ml}$ of water (T1) feed formulation yielded the highest mean weight gain of 0 . niloticus (nile tilapia). Further, the weight gain of $O$. niloticus (nile tilapia) for $25 \mathrm{~g} \mathrm{MW}+40 \mathrm{~g}$ CS $+33 \mathrm{ml}$ of water (T1) was highly significant at $\alpha \leq 0.01$.
The number of live 0 . niloticus (nile tilapia) in Table 4 showed the percent survival of juvenile 0 . niloticus (nile tilapia) fed with T. molitor (mealworm) larvae pellet.

\begin{tabular}{|c|c|}
\hline Treatments & Percent Survival (\%) \\
\hline T1 (25g mealworm larvae + 44g cassava starch $+33 \mathrm{ml}$ water) & $100 \%$ \\
\hline T2 (50g mealworm larvae + 40g cassava starch $+38 \mathrm{ml}$ water) & $100 \%$ \\
\hline T3 (75g mealworm larvae + 40g cassava starch $+46 \mathrm{ml}$ water) & $100 \%$ \\
\hline T4 (Commercial fish pellets) & $100 \%$ \\
\hline
\end{tabular}

Table 4: Percent survival of juvenile $O$. niloticus (nile tilapia) fed with T. molitor (mealworm) larvae feed formulations.

The one hundred eighty (180) 0 . niloticus utilized in the experimental study survived the 30 -days feeding trial. Thus, the results showed $100 \%$ survival rate of 0 . niloticus fed with T. molitor larvae feed formulations.
In terms of the pellet's stability, all of the formulated feeds were still stable at 5.5 hours' time as the feeds given out did not disintegrate during the span of time. Since the time interval of the feeding is 6:30 am-12:00 nn-6:30 pm, 


\section{International Journal of Oceanography \& Aquaculture}

the experiment conducted was delimited to 5.5 hours' time as new feeds will be introduced after.

According to Garcia-Maraver, et al. [12], pellet quality depends on the properties of the feedstock itself such as the biomass type, particle size, and binding agent. Suitable condition of these factors is necessary to obtain a good quality pellet. In addition, according to Agriculture
Information, a factor such as temperature and humidity, storage conditions, and even oxygen pressure contributes to the viability of the pellet.

Figure 2 shows the condition of the different formulated pellets after 6 months' time stored at room temperature.

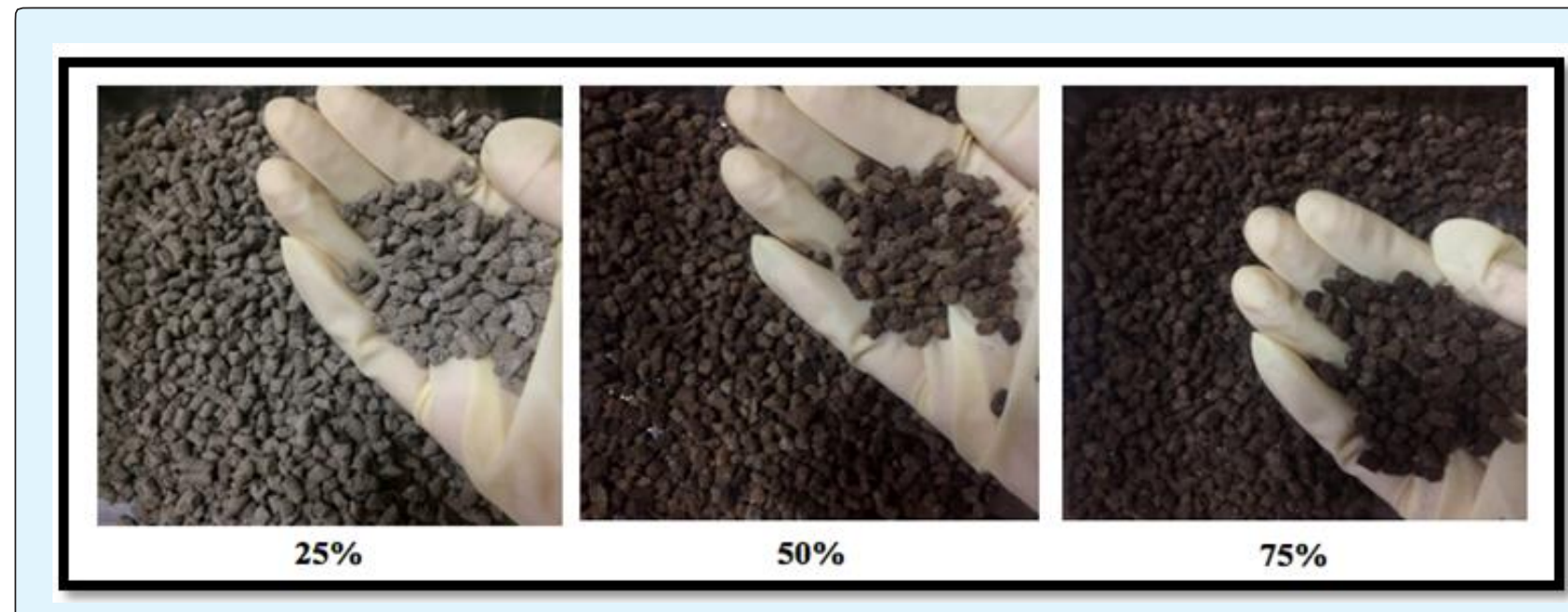

Figure 2: Condition of the different pellet formulation after 6 months' time.

The calculation of the cost of investment (COI) revealed that the $O$. niloticus harvested at its $30^{\text {th }}$ day is not yet profitable and harvestable at 30 days. However, in terms of the income, treatment $1(25 \mathrm{~g} \mathrm{MW}+40 \mathrm{~g} \mathrm{CS}+$ $33 \mathrm{ml}$ of water) obtained the highest income (P100.18) and the minimal expenses (P46.47). This is supported by Food and Agriculture Organization [6] which states that it will take 5 months for the $O$. niloticus (nile tilapia) to reach its marketable size (300-500 g). Accordingly, nile tilapia that is greater than 25 grams requires approximately $28-30 \%$ protein for optimum growth. Mealworm larvae contain approximately 49.1 of protein along with its essential amino acids in their body $[4,13]$. With this, Tenebrio molitor (mealworm) larvae can provide the necessary requirement to allow the $O$. niloticus (nile tilapia) achieved better gain weight.

\section{Conclusion and Recommendations}

There is a highly significant difference in terms of the mean gain weight (grams) of 0 . niloticus (nile tilapia) between and within groups after being fed with the different feed formulations and treatment 1 with $25 \%$ mealworm larvae, $40 \mathrm{~g}$ cassava starch and $33 \mathrm{ml}$ water showed the most efficient feed formulation. There was $100 \%$ survival of 0 . niloticus fed with T. molitor larvae feed formulation and the formulated feeds did not disintegrate in the pond water in 5 to 6 hours' time. However, at 30 days' feeding trial, 2 months old $O$. niloticus is not yet profitable. It is recommended to conduct a 5 month-feeding trial to clearly see the difference of $O$. niloticus (nile tilapia) growth performance on $25 \%$ T. molitor (mealworm) larvae feed formulation and to further validate its cost of investment (COI). A proximate analysis on the $25 \%$ T. molitor (mealworm) larvae feed formulation is also recommended.

\section{References}

1. Delgado C, Wada N, Rosegrant M (2003) World Fish. International Food Policy Research Institute.

2. Thevenot A, Rivera J, Wilfart A, Maillard F, Hassouna $M$, et al. (2017) Mealworm meal for animal feed: Environmental assessment and sensitivity analysis to guide future prospects. Journal of Cleaner Production 170: $1260-1267$. 


\section{International Journal of Oceanography \& Aquaculture}

3. (2004) Department of Agriculture, Bureau of Fisheries and Aquatic Resources (DA-BFAR).

4. Hussain I, Khan S, Sultan A, Chand N, Khan R, et al.(2017) Mealworm (Tenebrio molitor) as potential alternative source of protein supplementation in broiler. International Journal of Biosciences 10(4): 255-262.

5. Romana-Eguia MRR, Larona MA, Catacutan MR (2013) On-farm feed management practices for Nile tilapia (Oreochromis niloticus) in the Philippines. SEAFDEC Aquaculture Department (SEAFDEC/AQD).

6. (2018) Food and Agriculture Organization of the United Nations.

7. Nakkina M (2016) Study of Growth Rate in Nile Tilapia (Oreochromis niloticus). Journal of Aquaculture Research and Development 7(8): 440.

8. Dedeke GA, Owa SO, Olurin KB, Akinfe AO, Awotedu 00, et al. (2013) Partial replacement of fish meal by earthworm meal (Libyodrilus violaceus) in diets for African catfish, Clarias gariepinus. International Journal of Fisheries and Aquaculture 5(9): 229-233.
9. Royes J, Chapman F (2015) Preparing your own Fish Feeds. Fisheries and Aquatic Sciences Department, university of Florida.

10. Pucher J, Ngoc TN, Thi Hanh Yen T, Mayrhofer R, ElMatbouli M, et al. (2014) Earthworm Meal as Fishmeal Replacement in Plant based Feeds for Common Carp in Semi-intensive Aquaculture in Rural Northern Vietnam. Turkish Journal of Fisheries and Aquatic Sciences 14: 557-565.

11. Panase P, Mengumphan K (2015) Growth performance, Length-Weight Relationship and Condition Factor of Backcross and Reciprocal Hybrid Catfish reared in Net Cages. International Journal of Zoological Research 11(2): 57-64.

12. Garcia-Maraver A, Rodriguez ML, Serrano-Bernardo F, Diaz LF (2015) Factors affecting the quality of pellets made from residual biomass of olive trees. Fuel Processing Technology 129: 1-7.

13. Dalzell P, Corpuz P, Ganaden R, Pauly D (1987) Estimation of Maximum Sustainable Yield and Maximum Economic Rent from the Philippine Small Pelagic Fisheries. BFAR Technical Paper Series 10(3): 23. 